Research Paper

\title{
Influence of glyphosate in planktonic and biofilm growth of Pseudomonas aeruginosa
}

\author{
Ilana Schneider Lima ${ }^{1}$, Nicole Carmo Baumeier ${ }^{1}$, Rosimeire Takaki Rosa ${ }^{2}$, \\ Patrícia Maria Stuelp Campelo ${ }^{2}$, Edvaldo Antonio Ribeiro Rosa ${ }^{2}$ \\ ${ }^{1}$ Curso de Odontologia, Escola de Saúde e Biociências, \\ Pontifícia Universidade Católica do Paraná, Curitiba, PR, Brazil. \\ ${ }^{2}$ Unidade de Pesquisa com Xenobióticos, Escola de Saúde e Biociências, \\ Pontifícia Universidade Católica do Paraná, Curitiba, PR, Brazil.
}

Submitted: June 18, 2013; Approved: December 13, 2013.

\begin{abstract}
This study evaluated the impact of different concentrations of glyphosate (Rondup ${ }^{\mathbb{B}}$ ) on planktonic and biofilm growth of $P$. aeruginosa. Aerobic and anaerobic cultures of $P$. aeruginosa ATCC $^{\circledR} 15442$ inoculated in MHB + glyphosate $(0.845 \mathrm{ppm}, 1.690 \mathrm{ppm}, 8.45 \mathrm{ppm}, 16.90 \mathrm{ppm}, 84.50 \mathrm{ppm}, 169 \mathrm{ppm}$, $845 \mathrm{ppm}$, and $1690 \mathrm{ppm}$ ) and cultured in normoxia and anoxia, following their $\mathrm{OD}_{560 \mathrm{~nm}}$ every hour for $24 \mathrm{~h}$. Biofilms of adapted cells were formed in the presence of glyphosate ( 0.845 to $1690 \mathrm{ppm})$ in normoxia and anoxia for $36 \mathrm{~h}$. Glyphosate at concentrations higher than $84.5 \mathrm{ppm}$ reduces the cell density of planktonic aerobic cultures $(\mathrm{p}<0.05)$. However, these same concentrations favor the planktonic anaerobic growth $(\mathrm{p}<0.05)$. On the other hand, the herbicide favors a slight growth of biofilms in a concentration-dependent manner up to $84.5 \mathrm{ppm}(\mathrm{p}>0.05)$, and more pronounced over $169 \mathrm{ppm}$. Anaerobic biofilms have their growth more readily favored $(\mathrm{p}<0.05)$, regardless of concentration. In a concentration-dependent manner, glyphosate interferes with the growth ability of $P$. aeruginosa $\mathrm{ATCC}^{\mathbb{B}} 15442$.
\end{abstract}

Key words: Pseudomonas aeruginosa, glyphosate, growth, biofilm.

\section{Introduction}

Glyphosate (N-phosphonomethylglycine, CAS $\mathrm{N}^{\circ}$ 1071-83-6) is a non-selective systemic herbicide that is widely used to control post-emergent weeds in plantations and commercial forests. Worldwide, the best known formulation is produced under the trade name Rondup ${ }^{\circledR}$, although there are many generic products. In Brazil, the commercial formulation of Rondup ${ }^{\circledR}$ consists of 36\% glyphosate isopropilaminic salt (active ingredient) and 18\% polioxyethylenamin (POEA-surfactant, CAS $\mathrm{N}^{\circ}$ 6179126-2). Other formulations, such as Rodeo $^{\circledR}$ do not have POEA in their formulation (Tsui et al., 2004).

Although the discussion about its role as a pollutant is relevant and there is a concern about possible risks of intoxication (Stella and Ryan, 2004) and genotoxicity (Dallegrave et al., 2007), very little attention has been directed to possible interactions with autochthonous human/animal microbiota, especially that with pathogenic potential. Studies to assess any influence of glyphosate or its associations on microorganisms are focused in soil and aquatic microbiomes showing a variable capacity to increase or decrease specific microbial groups (Araújo et al., 2003; Means et al., 2007; Pérez et al., 2007).

Pseudomonas aeruginosa is a gram-negative organism associated with a myriad of diseases varying from mild cutaneous infections to complicated pulmonary complications of cystic fibrosis (Govan and Deretic, 1996). It is a free-living bacterium naturally occurring in water. Surface waters can be contaminated by glyphosate due to the overuse of herbicides and to rainfalls. Due to its similarity with amino acids, it is feasible to assume that exposure to glyphosate can interfere in bacterial metabolism with shifts in biological and/or virulence characteristics.

Send correspondence to E.A.R. Rosa. Unidade de Pesquisa com Xenobióticos. Escola de Saúde e Biociências, Pontifícia Universidade Católica do Paraná, Rua Imaculada Conceição 1155, 80215-901 Curitiba, PR, Brazil. Email: edvaldo.rosa@pucpr.br. 
Given the significant medical importance of $P$. aeruginosa and the fact that it is a water-borne organism, it is justifiable a study to prospect the influence of this and other herbicides, as well as other classes of pesticides, in the biology of bacteria and in the pathogenesis of their related infections.

As studies evaluating the herbicide-pathogenic microbiota interactions of are virtually nonexistent, the proposition of this study was to assess the impact that the commercial product Rodeo $^{\circledR}$ exerts on $P$. aeruginosa $\mathrm{ATCC}^{\circledR} 15442$ regarding to its cell viability, adhesion ability, and biofilm formation.

\section{Material and Methods}

\section{Interference on planktonic growth}

Pseudomonas aeruginosa ATCC ${ }^{\circledR} 15442$ was grown in 1:10 Mueller-Hinton Broth plus glyphosate (at 0.845 ppm, 1.690 ppm, 8.45 ppm, 16.90 ppm, 84.50 ppm, $169 \mathrm{ppm}, 845 \mathrm{ppm}$, and $1690 \mathrm{ppm}$ ) in normoxia and anoxia $\left(90 \% \mathrm{~N}_{2}, 10 \% \mathrm{CO}_{2}\right)$ until an $\mathrm{OD}_{560}$ of 0.50 . This step was repeated twice, to allow to cells to adapt to the distinct atmospheric conditions and to the xenobiotic presence. After adaptation, aliquots of $200 \mu \mathrm{L}$ of suspensions containing ca. $1 \times 10^{7}$ cfu. $\mathrm{mL}^{-1}$ were subcultured into tubes containing 2 $\mathrm{mL}$ of 1:10 Mueller-Hinton Broth plus glyphosate (at 0.845 ppm, 1.690 ppm, 8.45 ppm, 16.90 ppm, 84.50 ppm, 169 ppm, $845 \mathrm{ppm}$, and $1690 \mathrm{ppm})$. The tubes were adapted to a blood rotative mixer and incubated at $37^{\circ} \mathrm{C}$ and $10 \mathrm{rpm}$, in anoxic and normoxic conditions. Growth curves were built after spectrophotometric readings at $560 \mathrm{~nm}$ taken every hour for twenty-four hours without interruption.

The anoxic technique used was that of Wolfe (2011). Anoxic conditions were maintained by displacing all air in culture broth with $\mathrm{CO}_{2}$ made $\mathrm{O}_{2}$ free by passage over heated copper. Mueller-Hinton Broth used for anoxic cultures was not pre-reduced. It was autoclaved and, still warm, it was aseptically vacuum-degassed under vigorous shaking. Once at room temperature, flask's headspace was filled with sterile $\mathrm{N}_{2}$ and sterile glyphosate was added. Broth was carefully transferred to sterile screw capped culture tubes bearing butyl rubber seals in which bacterium inocula were previously dispensed $(200 \mu \mathrm{L}$ of suspensions containing ca. $1 \times 10^{7}$ cfu. $\mathrm{mL}^{-1}$ ).

To ascertain that turbidity was dependent only to cell density and not to extracellular polymeric substances, parallel anoxic/normoxic incubations were conducted with extra tubes. Each 4-h of incubation, $20 \mu \mathrm{L}$ aliquots were harvested, streaked onto glass slides and stained with Congo Red. In all cases, optical microscopy revealed that no extracellular matter has been produced (data not shown).

\section{Interference in the formation of biofilms}

Aerobic or anaerobic cell suspensions of $P$. aeruginosa $\mathrm{ATCC}^{\circledR} 15442$ containing ca. $1 \times 10^{8}$ cfu.mL $^{-1}$ were adhered onto 96-well polystyrene wells coated with sterile $0.1 \% \mathrm{~L}$-asparagine for $4 \mathrm{~h}$ at $37{ }^{\circ} \mathrm{C}$. Polystyrene attached L-asparagine acts as anchoring points to bacterial fimbriae. Anoxic incubations were carried out in sealed jars connected to an in house evacuation-repletion gas system $\left(1^{\text {st }}\right.$ and $2^{\text {nd }}$ injections with $\mathrm{N}_{2}$ and $3^{\text {th }}$ injection with $90 \%$ $\mathrm{N}_{2} / 10 \% \mathrm{CO}_{2}$ ).

After the period of adhesion, supernatants were removed and wells were washed with sterile $145 \mathrm{mM} \mathrm{NaCl}$ to remove non-adhered weakly adhered cells. Wells received $200 \mu \mathrm{L}$ aliquots of 1:10 Mueller-Hinton Broth plus glyphosate (at $0.845 \mathrm{ppm}, 1.690 \mathrm{ppm}, 8.45 \mathrm{ppm}, 16.90 \mathrm{ppm}$, $84.50 \mathrm{ppm}, 169 \mathrm{ppm}, 845 \mathrm{ppm}$, and $1690 \mathrm{ppm}$ ). Wells were incubated in anoxic or normoxic atmosphere for $24 \mathrm{~h}$ and $37{ }^{\circ} \mathrm{C}$. Wells filled with 1:10 Mueller-Hinton Broth plus glyphosate at different concentrations served as negative controls. Positive controls were wells with L-asparagine and 1:10 Muller-Hinton Broth without glyphosate in which bacterial cells have grown as biofilm.

At the end of incubations, wells were aspirated and washed with $145 \mathrm{mM} \mathrm{NaCl}$. Biofilms were fixed with $200 \mu \mathrm{L}$ of $99 \%$ methanol (15 min). Methanol was removed and plates were air dried. Aliquots of $200 \mu \mathrm{L}$ of $0.5 \%$ crystal violet $(\mathrm{CV})$ were added to the wells. After $20 \mathrm{~min}$, excess of $\mathrm{CV}$ was removed by washing with water. Finally, the impregnated $\mathrm{CV}$ was released by adding $33 \%$ acetic acid $(150 \mu \mathrm{L})$ and the $\mathrm{OD}_{590 \mathrm{~nm}}$ was determined. Negative controls were wells with L-asparagine and 1:10 MullerHinton Broth plus glyphosate (at 0.845 ppm, 1.690 ppm, 8.45 ppm, 16.90 ppm, 84.50 ppm, 169 ppm, 845 ppm, and $1690 \mathrm{ppm}$ ) but without bacterial cells. Positive controls were wells washed with L-asparagine and filled with 1:10 Muller-Hinton Broth without glyphosate in which bacterial cells were challenged to form biofilms. Absorbance values of the blanks were subtracted from values obtained in treatments to eliminate spurious results due to background interference.

\section{Statistics}

All tests described above were carried out in triplicate in at least three different situations. Numeric data were tabulated in MSExcel $^{\circledR}$ spreadsheets (Microsoft Co.). Obtained data were tested for normal distribution by the Kolmogorov-Smirnov test and for homogeneity of variance by Chi-square test. To determine the interference in biofilms formation, the statistical differences were assessed using Tukey HSD test. Comparisons in a same glyphosate concentration in different atmospheres were carried out by Tukey test. A threshold of 0.05 was used to determine differences. Statistical analyzes were conducted using the package BioEstat 5.0 (IDS Mamirauá). 


\section{Results}

The growth curves containing lag, log and early stationary phases were constructed with $\mathrm{OD}_{540 \mathrm{~mm}}$ values read at one-hour intervals, for a total period of twenty-four hours (Figure 1). Aerobic growth was superior to anaerobic one. In normoxia, lower glyphosate concentrations $(0.845 \mathrm{ppm}$,
$1.690 \mathrm{ppm}, 8.45 \mathrm{ppm}, 16.90 \mathrm{ppm}$ ) seemed to favor planktonic cell growth. The most interesting finding occurred in anoxic atmosphere, where positive-control cultures, although adapted to the lack of oxygen, did not show good growth and cultures in the presence of higher concentrations of glyphosate have markedly developed (cluster "c" in Figure 1).

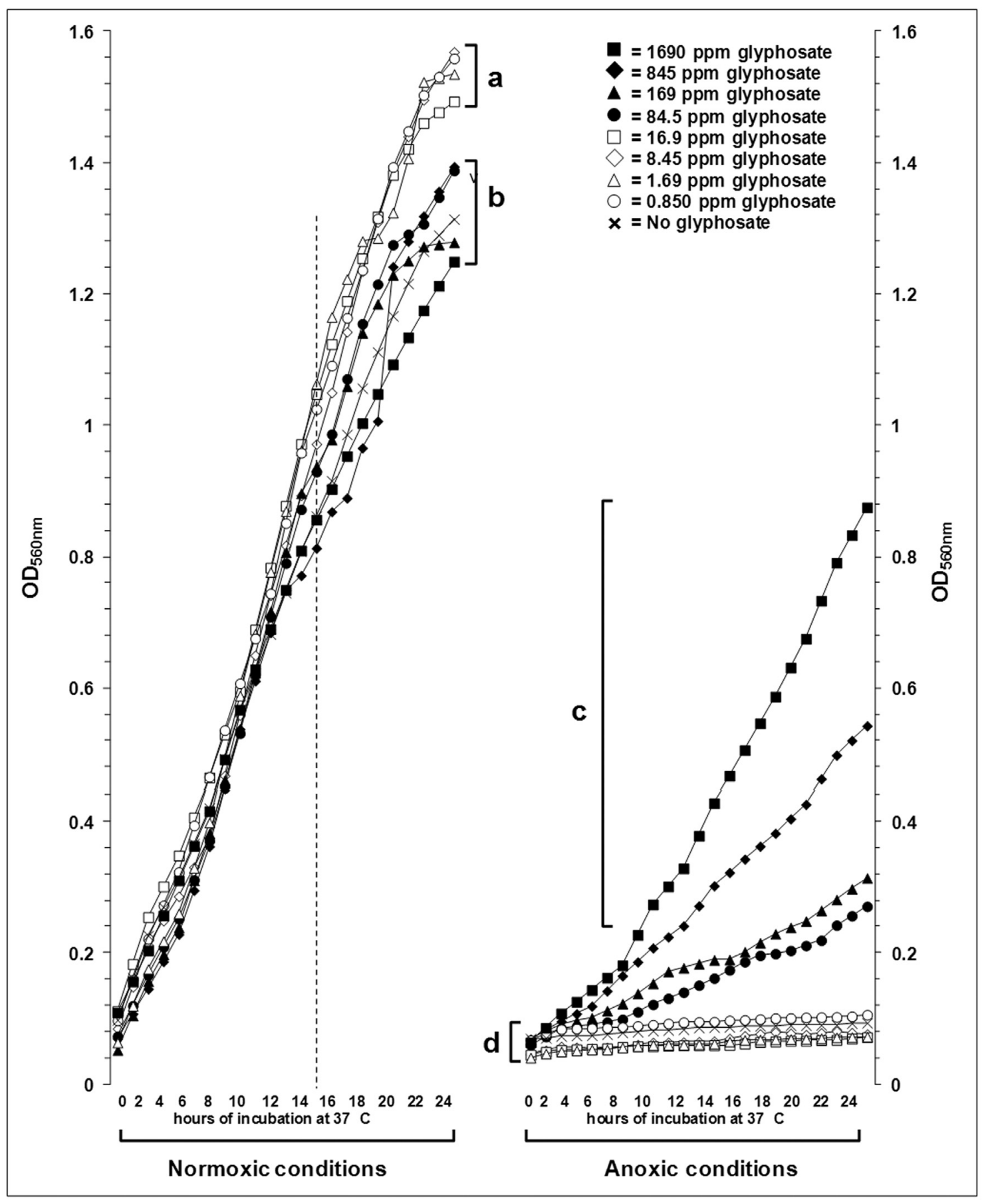

Figure 1 - Growth of $P$. aeruginosa $\mathrm{ATCC}^{\circledR} 15442$ in different concentrations of glyphosate and normoxic/anoxic conditions. Each point represents the arithmetical average of nine repetitions. Brackets arbitrarily group the final growths (i.e. after $24 \mathrm{~h}$ ) which present some quantitative similarity or that got apart from a compact cluster (for $84.5 \mathrm{ppm}$ to $1690 \mathrm{ppm}$ glyphosate in anoxic conditions). 
Regarding the aerobic growth, from $14-16 \mathrm{~h}$ postinoculation, there were detected two clusters. Cluster "a" comprises of glyphosate at concentrations below $16.9 \mathrm{ppm}$; on the other hand, cluster "b" comprises treatments with $84.5 \mathrm{ppm}$ to $1690 \mathrm{ppm}$ and the glyphosate-free control.

Biofilms of P. aeruginosa ATCC ${ }^{\circledR} 15442$ had more cells when were formed in absence of molecular oxygen ( $\mathrm{p}<0.05)$; among the different treatments, the only exception occurred in $0.845 \mathrm{ppm}$ glyphosate, where the means did not differ $(\mathrm{p}>0.05)$, although there seems to be a trend of increase in anoxia (Figure 2). Above $169 \mathrm{ppm}$, biofilms formed in anoxia retained more crystal violet, indicating higher cell content (Tukey HSD, $\mathrm{p}<0.05$ ). The same occurred with biofilms formed in normoxia at concentrations above 845 ppm (Tukey HSD, $p<0.05$ ). A greater range of variation between biofilms formed in different atmospheres occurred at $1690 \mathrm{ppm}$ (Student's t test, $\mathrm{p}=0.0003$ ).

\section{Discussion}

Glyphosate is probably the herbicide most discharged into the environment. Due to its extensive use in the protection of crops, it is inevitable that it will reach surface and deep waters (Pournaras et al., 2007), especially after rainfalls. The concentrations of glyphosate used herein are slightly higher than those found in surface waters after rainfalls (Peruzzo et al., 2008); however, as it is not possible to establish a consensus in terms of concentration, once it depends on variations in the amount applied, rainfall intensity, and degradation, we assumed that such dissonance should not be a major factor.

Aerobic planktonic growth was superior to anaerobic one. This points to the possibility of $P$. aeruginosa, although a facultative organism (Davies et al., 1989; Yoon et al., 2002), has its growth significantly favored by the presence of molecular oxygen. Continuous bacterial exposure to low concentrations of glyphosate leads to increased rates of aerobic growth, which is somehow in agreement with previously published findings (Fitzgibbon and Braymer, 1988). By the contrary, in conditions of inaccessibility of molecular oxygen, the bacterium started to grow better in a concentration-dependent manner. It is possible that this phenomenon results from the use of the molecule as a source of phosphorus, as previously reported for the genus Pseudomonas (Peñaloza-Vazquez et al., 1995; Moore et al., 1983; Talbot et al., 1984). Glyphosate could also serve

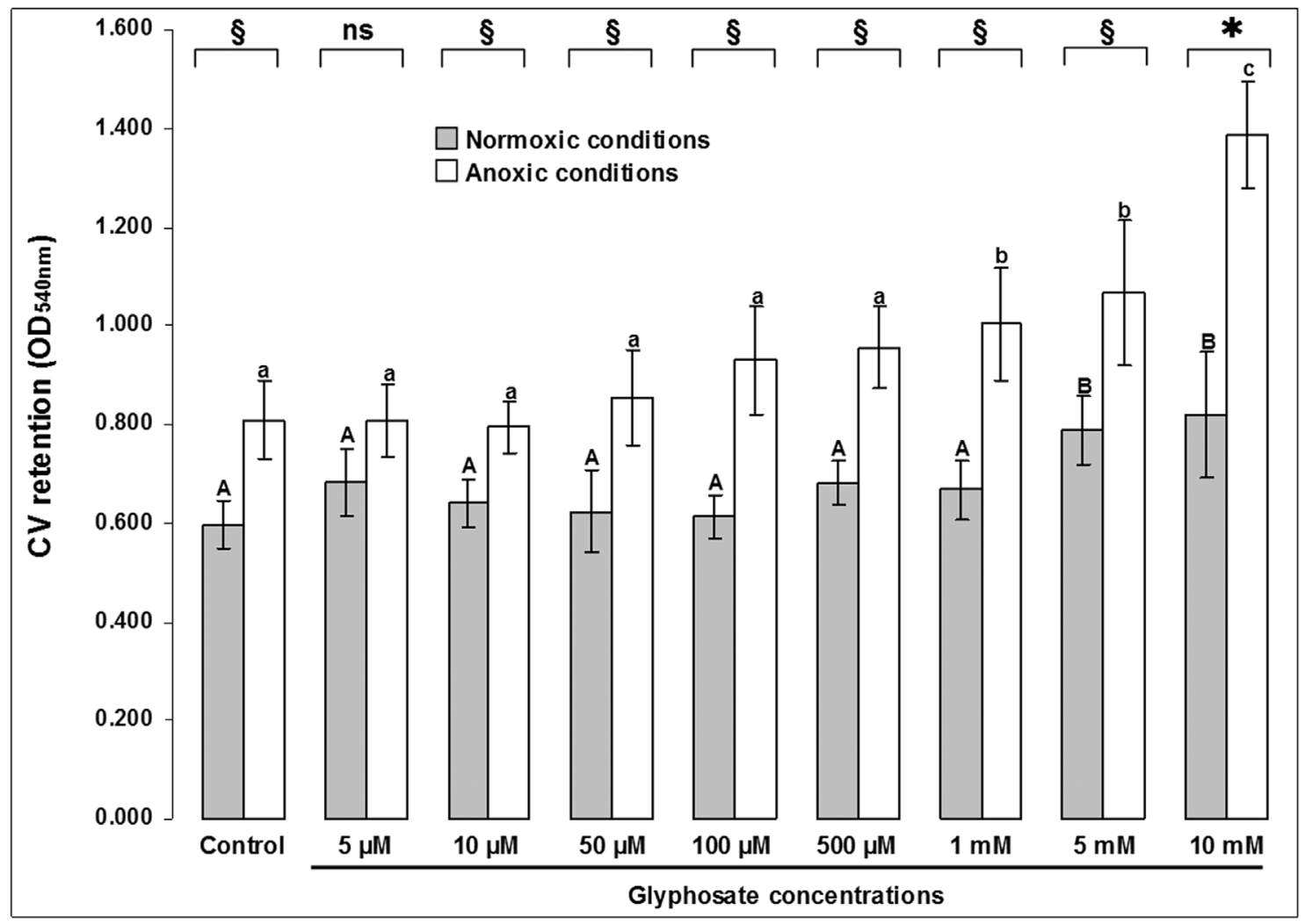

Figure 2 - Differential growth of 36 h-biofilms of $P$. aeruginosa ATCC ${ }^{\circledR} 15442^{\text {TM }}$ in different concentrations of glyphosate and in normoxic/anoxic conditions. Each bar represents the arithmetical average of nine repetitions with its respective $95 \%$ confidence interval. Different uppercase/lowercase letters over bars indicate differences among experimental groups (Tukey HSD test; $\mathrm{p}<0.05$ ), in function of different atmospheres, respectively. $\S=$ Existing differences among experimental groups in a given glyphosate concentration, in function of atmosphere (Student's $t$ test; $\mathrm{p}<0.05)$. $=$ Existing differences among experimental groups in a given glyphosate concentration, in function of atmosphere (Student's $t$ test; $\mathrm{p}<0.005$ ). ns $=$ Not significant differences (Student's $t$ test; $\mathrm{p}>0.05$ ). 
as a carbon source, which would be processed by both aerobic and anaerobic metabolisms (Rueppel et al., 1977), with increased rates in presence of oxygen. To support such theory, it has been found that different bacterial genera may promote catalysis of glyphosate using C-P lyases (van Eerd et al., 2003). Once broken up this connection, Pseudomonas spp. can produce glycine (Kishore and Jacob, 1987), which can also enhance growth.

To our knowledge, no other group has evaluated the effects that glyphosate can exert on sessile bacterial communities, so-called biofilms. Our results revealed that the xenobiotic tends to favor the formation of biofilms of $P$. aeruginosa, especially those anaerobic and that such increase seems to be concentration-dependent. Results of anaerobic planktonic and biofilm growth deserve greater reflection. In a hypothetical situation in which $P$. aeruginosa come to adhere to surfaces under low oxygen tensions and constant challenge of glyphosate, the growth can be incremented.

As Muller-Hinton broth, even ten-fold diluted, still is a culture medium with a complex composition and we may not ignore the possibility of some constituent had influenced the growth rates. However, this medium has been used in studies similar to this one, successfully (Alandejani et al., 2009; Pournaras et al., 2007).

The results from this study point to the fact that the indiscriminate use of agricultural formulations containing glyphosate may result in an increase in growth rates of planktonic and biofilm phenotypes of $P$. aeruginosa in watercourses or reservoirs.

\section{Acknowledgments}

The authors thank Professor Luiz Alberto Kozlowski (The Pontifical Catholic University of Paraná, Brazil), who kindly provided the glyphosate used in this study.

\section{References}

Alandejani T, Marsan J, Ferris W, Slinder R, Chan F (2009) Effectiveness of honey on Staphylococcus aureus and Pseudomonas aeruginosa biofilms. Otolaryngol Head Neck Surg 141:114-118.

Araújo AS, Monteiro RT, Abarkeli RB (2003) Effect of glyphosate on the microbial activity of two Brazilian soils. Chemosphere 52:799-804.

Dallegrave E, Mantese FD, Oliveira RT, Andrade AJ, Dalsenter PR, Langeloh A (2007) Pre and postnatal toxicity of the commercial glyphosate formulation in Wistar rats. Arch Toxicol 81:665-673.

Davies KJ, Lloyd D, Boddy L (1989) The effect of oxygen on denitrification in Paracoccus denitrificans and Pseudomonas aeruginosa. J Gen Microbiol 135:2445-2451.
Fitzgibbon J, Braymer HD (1988) Phosphate starvation induces uptake of glyphosate by Pseudomonas sp. strain PG2982. Appl Environ Microbiol 54:1886-1888.

Govan JR, Deretic V (1996) Microbial pathogenesis in cystic fibrosis: mucoid Pseudomonas aeruginosa and Burkholderia cepacia. Microbiol Rev 60:539-574.

Kishore GM, Jacob GS (1987) Degradation of glyphosate by Pseudomonas sp. PG2982 via a sarcosine intermediate. J Biol Chem 262:12164-12168.

Means NE, Kremer RJ, Ramsier C (2007) Effects of glyphosate and foliar amendments on activity of microorganisms in the soybean rhizosphere. J Environ Sci Health B 42:125-132.

Moore JK, Braymer HD, Larson AD (1983) Isolation of a Pseudomonas sp. which utilizes the phosphonate herbicide glyphosate. Appl Environ Microbiol 46:316-320.

Peñaloza-Vazquez A, Mena GL, Herrera-Estrella L, Bailey AM (1995) Cloning and sequencing of the genes involved in glyphosate utilization by Pseudomonas pseudomallei. Appl Environ Microbiol 61:538-543.

Pérez GL, Torremorell A, Mugni H, Rodríguez P, Solange Vera M, do Nascimento M, Allende L, Bustingorry J, Escaray R, Ferraro M, Izaguirre I, Pizarro H, Bonetto C, Morris DP, Zagarese H (2007) Effects of the herbicide Roundup on freshwater microbial communities: a mesocosm study. Ecol Appl 17:2310-2322.

Peruzzo PJ, Porta AA, Ronco AE (2008) Levels of glyphosate in surface waters, sediments and soils associated with direct sowing soybean cultivation in north pampasic region of Argentina. Environ Pollut 156:61-66.

Pournaras S, Ikonomidis A, Markogiannakis A, Spanakis N, Maniatis AN, Tsakris A (2007) Characterization of clinical isolates of Pseudomonas aeruginosa heterogeneously resistant to carbapenems. J Med Microbiol 56:66-70.

Rueppel ML, Brightwell BB, Schaefer J, Marvel JT (1977) Metabolism and degradation of glyphosphate in soil and water. J Agric Food Chem 25:517-528.

Stella J, Ryan M (2004) Glyphosate herbicide formulation: a potentially lethal ingestion. Emerg Med Australas 16:235-239.

Talbot HW, Johnson LM, Munnecke DM (1984) Glyphosate utilization by Pseudomonas sp. and Alcaligenes sp. isolated from environmental sources. Curr Microbiol 10:255-259.

Tsui MT, Chu LM (2004) Comparative toxicity of glyphosate-based herbicides: aqueous and sediment porewater exposures. Arch Environ Contam Toxicol 46:316-323.

van Eerd LL, Hoagland RE, Zablotowicz RM, Hall JC (2003) Pesticide metabolism in plants and microorganisms. Weed Sci 51:472-495.

Yoon SS, Hennigan RF, Hilliard GM, Ochsner UA, Parvatiyar K, Kamani MC, Allen HL, DeKievit TR, Gardner PR, Schwab U, Rowe JJ, Iglewski BH, McDermott TR, Mason RP, Wozniak DJ, Hancock RE, Parsek MR, Noah TL, Boucher RC, Hassett DJ (2002) Pseudomonas aeruginosa anaerobic respiration in biofilms: relationships to cystic fibrosis pathogenesis. Dev Cell 3:593-603.

Wolfe RS (2011) Techniques for cultivating methanogens. Methods Enzymol 494:1-22.

All the content of the journal, except where otherwise noted, is licensed under a Creative Commons License CC BY-NC. 